\title{
Raça e pensamento social brasileiro
}

\section{Breitner Tavares ${ }^{1}$}

\begin{abstract}
Resumo: O objetivo deste artigo é apresentar uma reflexão sobre os intelectuais, para se pensar como este grupo, estruturado de determinadas formas, assume a posição de fomentadores de um discurso sobre a categoria raça como elemento na construção de uma identidade nacional brasileira. De fato, as condições que estabelecem o surgimento de um segmento como dos intelectuais são diversas, diferenciando-se no tempo e no espaço o que sugere primeiramente, uma definição mais geral do sentido de termo 'intelectual'. Em seguida será discutida a questão da identidade e da formação de um sentimento de pertencimento da nação. A categoria raça, entendida como um desses referenciais discursivos dentro do pensamento social brasileiro será localizada nos textos de alguns intelectuais. Também serão consideradas algumas contribuições de movimentos sociais interessados na formulação de uma teoria do tipo étnico brasileiro enquanto povo, e do Brasil como nação. $\mathrm{O}$ que estava em jogo, nesse debate intelectual nacional, era fundamentalmente a questão de saber como transformar essa pluralidade de raças e mesclas, culturas e valores civilizatórios tão diferentes, identidades tão diversas, numa única coletividade de cidadãos, numa só nação e num só povo. Além disso, o conceito de raça foi utilizado de diversas formas para segregar os negros no Brasil que se organizaram politicamente para a reconstrução política desse conceito.
\end{abstract}

Palavras-chave: Raça, pensamento social, intelectuais, nação, moviomentos sociais no terceiro mundo.

\section{Race and brazilian social thought}

\begin{abstract}
The objective of this paper is to present a discussion about the intellectuals, and how they have some influence in the Brazilian public sphere developing different discourses about the race category in the social thinking. Furthermore, how this concept has been important to understand some elements in the construction of a Brazilian national identity. Taking race as a discursive approach inside of the Brazilian social thought. It will be located in the texts of some historical Brazilian writers. Based in that perspective we have on the one hand, some contributions from the social movements in the formularization of a theory about the Brazilian as an ethnic group, and on the other hand, we have some conceptions of Brazil as nation. The main point in this national intellectual debate, was basically the question how to understand the changing in this plurality of races and mixtures, cultures and civilizatory values, between many identities, in an only one self perception about been Brazilian citizens. Moreover, the race concept has been used in diverse forms to segregate the black people in Brazil that if had politically organized for the reconstruction politics of this concept.
\end{abstract}

Key-words: Race, social thought, intellectuals, nation, social movements in the third world.

${ }^{1}$ Doutor em Sociologia, Professor do Instituto de Ciências Sociais da Universidade Federal de Alagoas - UFAL. E-Mail: btavares.ufal@gmail.com 


\section{Introdução}

O objetivo deste artigo é apresentar uma reflexão sobre os intelectuais, para se pensar como este grupo, estruturado de determinadas formas, assume a posição de fomentadores de um discurso sobre a categoria raça como elemento na construção de uma identidade nacional brasileira.

De fato as condições que estabelecem o surgimento de um segmento como dos intelectuais são diversas, diferenciando-se no tempo e no espaço o que sugere primeiramente, uma definição mais geral do sentido de termo 'intelectual'. Em seguida será discutida a questão da identidade e da formação de um sentimento de pertencimento da nação.

A categoria raça, entendida como um desses referenciais discursivos dentro do pensamento social brasileiro será localizada nos textos de alguns intelectuais como Silvio Romero, Euclides da Cunha, Alberto Torres, Manoel Bonfim, Nina Rodrigues, Oliveira Viana, Gilberto Freyre, Florestan Fernandes, Abdias do Nascimento entre outros. Também serão consideradas algumas contribuições de movimentos sociais como o Teatro Experimental Negro - TEN e a Frente Negra Nacional. Todos estavam interessados na formulação de uma teoria do tipo étnico brasileiro enquanto povo e do Brasil como nação. $\mathrm{O}$ que estava em jogo, nesse debate intelectual nacional, era fundamentalmente a questão de saber como transformar essa pluralidade de raças e mesclas, culturas e valores civilizatórios tão diferentes, identidades tão diversas, numa única coletividade de cidadãos, numa só nação e num só povo.

\section{Intelectuais: alguns aportes}

Na modernidade, onde ocorre um maior processo de racionalização, surge uma possibilidade de um tipo "auto avaliação" dos sujeitos sociais, que passam a se perceberem como parte de uma organização e que, além disso, podem interferir em seus processos conscientemente. Sob essa perspectiva se pode afirmar que um grupo "surge" na medida em que se estabelece uma consciência de sua posição num dado contexto. Isso ocorre "na medida em que um grupo critica sua definição decretada por outro, ele passa a criticar sua própria relação com esse outro grupo $^{\prime 2}$, cada grupo social tende a desenvolver sua própria perspectiva e a desengajar-se da interpretação pública da ordem existente. Mannheim estabelece o termo intelligentsia para definir este estágio último do desenvolvimento da consciência grupal, "um agregado situado 'entre', e não acima das classes", portanto, mais instável podendo cambiar seu posicionamento o que significa, uma menor rigidez no engajamento.

\footnotetext{
${ }^{2}$ Mannheim (1974, p. 74).
} 
O intelectual contemporâneo diferentemente dos demais indivíduos submetidos ao "continuum da experiência cotidiana", aprendizado tribal, esotérico e deixa de constituir uma casta ou um estamento fechado, passando a integrar um estado aberto, ao qual ganham acesso indivíduos das mais variadas procedências (da escolástica fechada ao processo intelectual). Os intelectuais são por excelência o grupo que possui autoconsciência por se questionarem permanentemente diante dos constrangimentos, por não representarem o interesse de uma classe social específica, possuem a capacidade de síntese racional dos processos irracionais da vida social e propor ações sociais. "O intelectual moderno tem pouco atrás de si e tudo à sua frente".

Cada grupo social dentro de estruturas materiais econômicas de um modo orgânico cria para si, uma ou mais camadas de intelectuais que the dão homogeneidade e consciência da própria função, não apenas no campo econômico, mas também no social, político e simbólico. Os intelectuais orgânicos são comissários do grupo dominante. Exercem as funções subalternas da hegemonia social, ou seja, o processo pelo qual os valores da classe dominante são disseminados, nas classes dominadas nas esferas política, ideológica, garantindo assim o consenso das grandes massas da população à direção imposta à vida social pelo grupo dominante. Gramsci (1978) já despertava a atenção para o papel de criação de consenso ideológico por parte da ação dos intelectuais.

\section{A formação de uma elite intelectual: fragmentos da imagem negra}

Até a Segunda metade do século XIX é possível, afirmar que no Brasil não houve uma divisão do trabalho intelectual, de modo que, se instituísse um grupo como intelectuais. $\mathrm{O}$ romantismo se manifestava através de um nacionalismo literário que incorpora elementos ainda sob um referencial europeu voltado para a idealização como visto no indianismo, nativismo e por um repudio a Portugal. O campo editorial era restrito, havia algumas revistas como a Niterói, um instrumento de coalizão entre os escritores bacharéis.

No século dezenove, com a vinda da família real portuguesa ao Brasil se inicia a instauração de um Estado, mas um Estado ainda "sem nação". Em 1838 é fundado o Instituto Histórico e Geográfico do Brasil (IHGB). Essa instituição produziria a "história oficial do Brasil" a parir de uma, historiografia e de uma teoria da escrita, na qual se enfatizou todo ideal nacionalista e personalista prevalecente, pelo discurso intelectual de escritores românticos. Nesses trabalhos se buscava a representação das categorias pátria, do território e da idealização do índio enquanto herói nacional. Até a metade do século XIX praticamente não há a presença do negro no debate intelectual institucional. Uma exceção seria algumas obras como a obra Memórias de um Sargento de Milícias de Manoel Antonio de Almeida. Nela são retratados alguns personagens urbanos do então Rio de Janeiro da época com especial destaque para alguns negros como Chico-Juca ainda retratado de forma racista como o negro temível e ameaçador. 
O Chico-Juca era um pardo, alto, corpulento, de olhos avermelhados, longa barba, cabelo cortado rente; trajava sempre jaqueta branca, calça muito larga nas pernas, chinelas pretas e um chapelinho branco muito à banda; ordinariamente era afável, gracejador, cheio de ditérios e chalaças; porém nas ocasiões de sarilho, como ele chamava, era quase feroz. Como outros têm o vicio da embriaguez, outros o do jogo, outros o do deboche, ele tinha o vicio da valentia; mesmo quando ninguém lhe pagava, bastava que lhe desse na cabeça, armava brigas, e só depois que dava pancadas a fartar é que ficava satisfeito; com isso muito lucrava: não havia taverneiro que the não fiasse e não o tratasse muito bem ${ }^{3}$.

Em relação a um espaço editorial negro, estudos como de Garcia (1997) e Santos (2005), enunciam que apesar de não adquirirem uma grande abrangência em termos de circulação havia uma série de pequenas publicações de jornais a partir do século XIX. Essas publicações que estabeleciam uma coalizão acerca de questões como educação e protesto para os leitores aos quais se dirigia.

Ao perseguir as datas festivas de aniversários, casamentos, batizados, festas e bailes, também os anúncios de morte e doenças, artigos assinados e reportagens, temos um quadro aproximado dos comportamentos, anseios, esperanças e reivindicações daquelas pessoas. $\mathrm{O}$ protesto contra o preconceito racial e a marginalização social, poesia, teatro, música, conselhos e fofocas que tinham o objetivo de indicar regras morais e de comportamento, bem como juízos afirmativos de uma identidade negra, tudo isso e muito mais se pode vislumbrar nessa imprensa ${ }^{4}$.

Há informações que desde a década de 30 do século XIX já circulavam os jornais cariocas O Homem de Cor, O Mulato, O Brasileiro Pardo, O Cabrito e O Meia Cara, publicados entre 1833 e 1867, os primórdios da imprensa negra brasileira. A maior parte destes periódicos foi criada por negros livres em meio à escravidão, eles estabeleceram, o que ficou conhecido como, imprensa mulata voltada para o questionamento naquele momento da defesa da igualdade das raças.

\section{Biologização da categoria raça}

Mais propriamente na Segunda metade do Século XIX por volta de 1870 há um rompimento com o romantismo em detrimento de uma perspectiva cientificista que influenciariam os intelectuais republicanos. Surge uma literatura naturalista com forte influencia positivista e o realismo. O negro passa a ser tematizado sob a perspectiva evolucionista articulada por argumentos advindos da biologia.

A abolição da escravatura seguida da Proclamação da República exigirá das próximas gerações a resolução da seguinte questão: o que seria o povo? Lança-se

\footnotetext{
${ }^{3}$ Ver Memórias de um Sargento de Milícias de Manuel Antônio de Almeida (1997, p. 68).

${ }^{4}$ Cf. Garcia (1997)
} 
sobre o debate das metamorfoses das raças e mestiços que gerariam o povo brasileiro. O discurso positivista, ainda se apresentava como um discurso legitimador, para a prática intelectual na esfera da política nacional. Os intelectuais, anteriormente destituídos de suas antigas posições, agora se apresentam como as autoridades capazes de discernir a realidade social do país, "uma administração científica dos homens e da natureza", portanto os intelectuais se apresentaram como "herdeiros de uma missão política".

A vida cerebral do Brasil gira em torno de dois centros: o mundo dos intelectuais e o dos governantes; os escritores, professores, homens de letras e de ciência, os artistas, no primeiro grupo; os políticos, os administradores, os funcionários, no segundo ${ }^{5}$.

Os intelectuais que num primeiro momento foram marginalizados na República ocupando uma posição de dependência assumem posições políticas ações no sentido de chamarem para si a posição de porta-vozes da nação (...) tornar-se um grupo capaz de promover ação social implicava em buscar traçar a política do país. ${ }^{6}$

Na verdade os intelectuais afirmavam que a nação brasileira já existia, "já estava inscrita na realidade" o ponto seria torná-la 'visível' cultural e politicamente, "do implícito, vangloriavam-se de produzir o explícito".

Sérgio Miceli observa que de fato ocorreram vários dilemas que levaram os intelectuais diante da força do regime autoritário a se posicionarem num discurso de cunho universalista onde o seu cerne era o nacionalismo. A defesa da questão nacional sob a perspectiva da "cultura brasileira" onde seriam produzidos, distribuídos e consagrados bens simbólicos a partir do Estado.

Em torno desse álibi quase perfeito ao dissimular os ganhos que auferem das encomendas oficiais, passaram a partir de então a manipular um sistema de queixas e louvores cujo destinatário são os mecenas do estamento burocrático e do qual podiam se servir consoante as oscilações de prestígio de que eram objetos de sua posição relativa nas lutas entre as facções dominantes nos centros de poder. ${ }^{7}$

A geração de 1870 até o início do século XX acompanha o surgimento das teorias racialistas que de modo positivista tentam explicações para um país formado a parir de varias raças que tende a "uma degeneração". Esse tipo de abordagem já se verificava em autores como Joaquim Nabuco e Sílvio Romero que em seu pensamento, afirmavam a crucial questão de se saber se a população brasileira, oriunda do cruzamento entre três raças (branca, negra e índia) tão distintas, poderia fornecer ao país uma feição própria, original. Acreditava-se no nascimento de um povo tipicamente brasileiro que resultaria da mestiçagem entre estas três raças e cujo processo de formação estava ainda em curso. Mas, desse

\footnotetext{
${ }^{5}$ Cf. Torres (apud Pécaut, 1990 p. 25).

${ }^{6}$ Pécaut (1990, p. 27).

${ }^{7}$ Veja-se Miceli (1979, p. 179).
} 
processo de mestiçagem do qual resultará a dissolução da diversidade racial e cultural e a homogeneização da sociedade brasileira, dar-se-ia a predominância biológica e cultural branca e o desaparecimento dos elementos não brancos.

Em seu livro As raças humanas e a responsabilidade penal no Brasil, cuja primeira edição data de 1894, Raimundo Nina Rodrigues, em desavença com Sílvio Romero, divergem da tese desenvolvida por este último, segundo a qual era possível desenvolver no Brasil uma civilização através das três raças. Uma adaptação imposta e forçada de espíritos atrasados a uma civilização superior provocaria desequilíbrios e perturbações psíquicas.

Falando dos efeitos da mistura de raças em termos de conduta e temperamento, Nina influenciado pelo pensamento de Spencer argumenta que as raças cruzadas estão profundamente degradadas e atribui essa degradação aos defeitos dos colonizadores de um povo atrasado. A criminalidade do mestiço brasileiro torna-se uma manifestação de fundo degenerativo e, portanto, ligada "as más condições antropológicas do cruzamento. Esta idéia permite-lhes argumentar contra o livre arbítrio "a capacidade intelectual é uma função de organização cerebral, sobre a qual nada pode a vontade, que por sua vez não é mais do que uma manifestação dessa mesma organização" $0^{\prime \prime}$.

Em Os Sertões (1902), Euclides da Cunha retoma a questão da existência de um tipo étnico caracteristicamente brasileiro, que resultaria da convergência dos cruzamentos sucessivos dos três grupos raciais originais. Divergindo de Silvio Romero, Euclides da Cunha pensa que existem vários tipos devidos à heterogeneidade racial, aos cruzamentos, ao meio físico e a variedade de situações históricas. Para ele, o mestiço, traço de união entre raças, é quase sempre um desequilibrado, um decaído, sem energia física dos ascendentes selvagens e sem atitude intelectual dos ancestrais superiores.

No pensamento de Cunha (1902), o Brasil não pode ser considerado como um povo, uma nação, porque é etnologicamente indefinido por falta de tradições nacionais uniformes. Percebe-se que ele ficou também preso às doutrinas racistas de sua época e na explicação do comportamento dos sertanejos que considera superiores aos mulatos degenerados.

Por seu turno, Dante Oliveira Leite (1983) ao analisar a obra de Euclides da Cunha, levanta aparentes contradições a respeito de sua posição sobre a mestiçagem. Se o sertanejo é um forte no pensamento de Cunha (1902), só se explica porque, ao contrário do mestiço do litoral, ele já constitui uma raça autônoma e, além disso, não é obrigado a enfrentar uma civilização superior à sua capacidade. Euclides supunha que o sertanejo constituía uma raça e, a partir dela, o Brasil poderia desenvolver uma nação autêntica. Visto dessa maneira, ele se opõe claramente a Sílvio Romero para quem o brasileiro futuro resultaria do "branqueamento" da população previa sucessivas ondas de imigrantes capazes de compensar a degeneração dos mestiços.

\footnotetext{
${ }^{8}$ Rodrigues (1957, p. 127).
} 
$\mathrm{Na}$ sua obra O problema brasileiro, Alberto Torres (1982) desloca diametralmente o eixo da discussão sobre a formação da nacionalidade e da identidade brasileiras. Para ele, a diversidade racial não constitui obstáculo à construção da identidade do povo brasileiro.

Nenhum dos povos contemporâneos é formado de uma raça homogênea e isto não lhes impediu de formar uma nação, moral, política e socialmente:

\begin{abstract}
(...) Se os indigenas, os africanos e seus descendentes não puderam "progredir e aperfeiçoar-se" isto não se deve a qualquer incapacidade inata, mas ao abandono em vida selvagem ou miserável, sem progresso possível. ${ }^{9}$
\end{abstract}

E, para fazer do Brasil uma nação é necessário, em primeiro lugar, entender que nas sociedades formadas por várias raças a solidariedade política, jurídica e econômica envolve o interesse atual e futuro de todas as raças, num mesmo interesse e num mesmo compromisso de apoio mútuo.

Segundo Skidmore, Torres (1982) via o problema do Brasil como algo a ser:

\begin{abstract}
"explicado a partir da exploração do país por estrangeiros, cuja rapidez levava ao esgotamento dos recursos naturais a uma taxa alarmante, ao crescente controle dos setores dinâmicos da economia por capitalistas e estrangeiros, $e$ ao abandono sistemático da população nacional em favor de imigrantes estrangeiros que recebiam privilégios especiais" ${ }^{\prime 10}$.
\end{abstract}

Manoel Bonfim, assim como Alberto Torres, constitui uma voz discordante das doutrinas racistas em voga na sua época. Realizou uma análise cuidadosa das causas históricas para entender o atraso relativo e o racismo do Brasil e da América Latina. Os problemas herdados da era colonial (mentalidade de enriquecimento rápido, a ausência de tradição científica ou empírica, combinadas com uma cultura hiperlegalista, arraigada conservadorismo político e ausência de organização social) figuram entre os elementos que explicariam esse atraso. Criticou a política populacional brasileira, por haver abandonado os ex-excravisados, depois da abolição. Constituiu um discurso transitório entre a perspectiva do positivismo evolucionista em direção as explicações sócio históricas recorrentes dos futuros intelectuais presente de modo marcante em seu livro América Latina e seus Males de Origem (1905). Observa procura estabelecer uma teoria da história onde as relações sociais são definidas pala relação entre parasitas e parasitados. Como na sua argumentação em relação ao escravismo no Brasil.

\footnotetext{
${ }^{9}$ Torres (1982, pp. 28-29).

${ }^{10}$ Skidmore (1976).
} 
É recorrente a utilização de metáforas da relação ecológica "desarmônica". Vespas sucumbem colméias de abelhas retirando-lhes todo mel; traças destroem formigueiros. Analogias em função do quadro histórico são construídas a partir de influências de biólogos naturalistas como Paul Combes ou Wasman. Desta forma, Bomfim (1905) constrói um quadro de conseqüências gerais e específicas do parasitismo nas novas sociedades.

\section{A fundação de uma nação: a missão da intelectualidade brasileira na invenção e consagração do mestiço}

Os intelectuais agem enquanto um grupo, que reivindica no contexto do Estado Novo uma autoridade, daqueles que podem "dominar" o discurso sobre o social. Na medida de sua inserção, em meio ao regime, passam a tematizar certas questões como a "cultura brasileira" ou "identidade nacional". Os intelectuais, dessa forma, são participantes de um sistema de poder, agentes da consciência e do discurso que também é sua parte integrante ${ }^{11}$. Marginalizados num primeiro momento do Estado Republicano "os homens de letras" buscam, a superação dentro de um sistema de interdependência, posicionando-se enquanto porta-vozes da nação, um grupo que fosse capaz de promover ação social implicava em buscar traçar a política do país. "Ainda não somos uma nação que se conheça, se estime, se baste, ou com mais acerto, somos uma nação que ainda não teve o ânimo de romper sozinha para frente numa projeção vigorosa e fulgurante de sua personalidade" ${ }^{\prime 2}$.

Segundo estudos de Velloso (1987) e Pécaut (1990) o Estado inclui de modo diverso os intelectuais modernistas, os termos "complexidade" e "ambigüidade" talvez expressem melhor um panorama composto pelas mais diferentes correntes de pensamento, como os modernistas, positivistas, integralistas, católicos e até socialistas. Mannheim ao tratar das características da intelligentsia observa que é perfeitamente possível que seus membros, tenham um posicionamento político e de classe, possa se alinhar em estruturas partidárias e suas ações podem efetivamente revelar interesses de cunho ideológico. "Mas além e acima dessas afiliações, ele é motivado pelo fato de seu treinamento o equipou para encarar os problemas do momento a partir de várias perspectivas e não apenas de uma". ${ }^{13}$

A intelligentsia estado-novista, apesar de trazer várias divergências ideológicas assumiu um posicionamento que trazia um ponto em comum, de cunho universalista: a posição enquanto uma 'vanguarda esclarecida', a serviço de uma hegemonia nacionalista e estatal que implicou num distanciamento em relação ao povo o qual simplesmente, deveria ser tutelado por suas instituições. A

\footnotetext{
${ }^{11}$ Sobre a questão da legitimidade dos intelectuais num sistema de verdade e poder veja Foucault (2002).

${ }^{12}$ Apud W. Martins (1977).

${ }^{13}$ Mannheim (1974, p.88).
} 
'autoconsciência' dentro de um sistema de verdade, de uma ordem discursiva sereia responsabilidade do intelectual, agora inserido nos estamentos burocráticos responsáveis pelo fomento e difusão de bens simbólicos identificadores. Várias instituições dinamizaram esta discussão sobre o nacional dentre elas, o MEC, SPHAN ${ }^{14}$ e o DIP.

A realidade brasileira, já era "algo posto", o importante era "falar em nome dos destituídos de capacidade de discernimento e expressão" os intelectuais seriam os indivíduos capacitados para conhecer o Brasil, representante da consciência nacional. "O trabalho intelectual deve traduzir as mudanças ocorridas no plano político". "Preocupando-se com a elaboração da cultura brasileira, os intelectuais não tinham consciência de negligenciar o problema político: estavam simplesmente convencidos de que a essência do político era o processo que conduziria ao advento de uma identidade cultural". A realização de um grande ideal nunca é obra coletiva das massas, mas sim de uma elite, de um grupo, de uma classe, que com ele se identifica, que pôr ele peleja. ${ }^{15}$

Os modernistas como avaliam Antônio Cândido (1980, pp.119-21) e Sérgio Buarque de Holanda criaram a noção de "modernidade cultural" a partir da antropofagia às idéias estrangeiras teriam um papel instrumental na construção de algo universal como deveria ser a nacionalidade brasileira: reunindo aspectos de vanguardas européias "na exploração dos alicerces da nacionalidade brasileira na busca de suas maneiras de ser, seus falares, sua diversidade étnica e cultural, e das indefinições que estão na raiz de sua inventividade" ${ }^{\prime 16}$

A questão racial até os anos 20 é compreendida pela perspectiva do determinismo biológico. A superação só ocorre mais adiante já nos idos dos anos 30. A perspectiva desenvolvida como crítica ao racismo científico, formulada sob a inspiração das idéias de Franz Boas sintetizadas em Raça linguagem e cultura (1940). Boas, apresenta de modo geral, uma dissociação entre cultura e raça e afirmava que cultura não é determinada pela raça. Alem disso, não existem raças puras e que as diferenças entre grupos humanos são geradas socialmente e não dadas naturalmente. Nesses termos, as desigualdades entre negros e brancos, para além do fenótipo, são atribuídas às relações sociais mais precisamente as relações entre as classes.

Gilberto Freyre estabeleceu um novo marco no pensamento social brasileiro em sua obra Casa Grande e Senzala (1933). Ela foi fundamental na sistematização do mito da mestiçagem e da positividade do negro, na construção de uma ideologia nacional. As relações raciais no Brasil ocorreriam sob um "equilíbrio de antagonismos". A violência e crueldade da escravidão e suas seqüelas seriam mediadas pela "cordialidade" das relações sociais entre negros e brancos.

\footnotetext{
${ }^{14}$ Um estudo sobre a formação de uma intelligentsia é o artigo de Mariza Veloso Motta Santos (1996).

${ }^{15}$ Trechos de Oliveira Vianna, citados por Medeiros (1978, p. 94).

${ }^{16}$ Pécault (1990, pp.26-27)
} 
Sob essa perspectiva, negros, brancos e índios são legitimados como formadores do povo brasileiro e a miscigenação é avaliada positivamente como qualidade que dá identidade ao tipo nacional. Símbolos da cultura negra foram, então, resgatados e valorizados como importantes elementos do sincretismo cultural brasileiro por pesquisadores como Edison Carneiro, Roger Bastide e Arthur Ramos. Trata-se da criação do negro enquanto alegoria. O Brasil encontra seu caminho rumo à civilização numa relação de positividade frente à mistura das raças. O mestiço passa a ser o referencia do tipo brasileiro. No cenário político há uma discreta supressão das questões raciais desfavoráveis ao negro. Pois a nova ideologia da mestiçagem, de cunho universalizante, omitiria as tensões sociais ao eliminar ideologicamente a diversidade racial naquilo que foi criticado mais adiante como mito da democracia racial.

\section{Os movimentos sociais negros}

Paralelamente ao debate intelectual intrínseco ao Estado Novo há a tentativa de vários grupos advindos dos movimentos sociais preocupados com a questão negra. Esses grupos organizados e produziam um debate sobre o sentido de ser negro e suas múltiplas implicações no campo da política e da cultura, através de jornais e publicações e produções artísticas. Em 1931 surge a idéia da formação da Frente Negra Brasileira (FNB). Ela irá constituir-se enquanto um movimento de caráter nacional, com repercussão internacional. Surgiu da obstinação de negros abnegados, como Francisco Lucrécio, Raul Joviano do Amaral, José Correia Leite. Afirmavam que estavam fazendo racismo ao contrário. Grupo de posições controvertidas às vezes consideradas extremistas ora apoiando teses monarquistas chamadas patrianovista. Isso se refletiu na trajetória da entidade. Uma visão direitista levou muito dos seus adeptos a posições simpáticas em relação ao integralismo e ao nazismo. Paradoxalmente, o conceito de raça é manipulado pelos frente-negrinos, que, no seu jornal $A V o z d a$ Raça, os quais apresentam como máxima: "Deus, Pátria, Raça e Família", que depois é modificado. Era o slogan decalcado diretamente do "Deus, Pátria e Família", da Ação Integralista. Apesar dessas contradições ideológicas, a FNB se desenvolveu rapidamente, criando núcleos em vários Estados do Brasil. Milhares de negros, nas principais áreas do país, aderem ao seu ideário e passam a ser seus membros. Em face dos êxitos alcançados, a FNB resolveu transformar-se em partido político, contudo, mais adiante com a imposição da censura é imposta que leva a sua extinção em 1938.

Outro importante movimento voltado pra a questão do negro foi o chamado Teatro Experimental Negro (TEN) criado pelo emblemático Abdias do Nascimento. É importante ressaltar que o teatro brasileiro ainda estava em sua fase inicial de nacionalização realizada pela contribuição de pessoas como Nelson Rodrigues em termos de "texto, dicção, encenação e impostação do espetáculo". O TEN foi um movimento de cultural voltado para a educação e arte, que propunha resgatar, no Brasil, os valores da pessoa humana e da cultura negro-africana, degradados e negados por uma sociedade dominante. Nascimento argumenta que desde os 
tempos da colônia o negro portava a bagagem mental de sua formação metropolitana européia, imbuída de conceitos pseudocientíficos sobre a inferioridade da raça negra. Segundo o próprio Nascimento "a menção pública do vocábulo negro provocava sussurros de indignação". Crítico, inclusive do movimento cultural da Semana de Arte Moderna de 22 em que se evitava mencionar as tensões raciais da sociedade brasileira. O próprio Mario de Andrade se posicionou contrário a formação do TEN. Por outro lado, Abdias do Nascimento também recebeu o apoio do advogado Aguinaldo de Oliveira Camargo, do pintor Wilson Tibério, há tempos radicado na Europa; Teodorico dos Santos e José Herbel. A estes cinco, se juntaram logo depois Sebastião Rodrigues Alves, militante negro; Arinda Serafim, Ruth de Souza, Marina Gonçalves, empregadas domésticas; o jovem e valoroso Claudiano Filho; Oscar Araújo, José da Silva, Antonieta, Antonio Barbosa, Natalino Dionísio, e tantos outros.

Contrario a idéia de democracia racial o TEN assumiu o discurso de négritude em termos de uma linguagem dramática. Participou do Primeiro Festival Mundial das Artes Negras, realizado em Dacar no ano de 1966. Com a conquista da independência do Senegal, Dacar havia se tornado a capital da négritude, movimento político-estético protagonizado pelos poetas antilhanos Aimée Césaire e Léon Damas e pelo Presidente do Senegal, poeta Léopold Senghor.

A négritude proporcionara ao movimento de libertação dos países africanos, grande impulso histórico e fonte de inspiração. Ao mesmo tempo, influenciaram profundamente a busca de caminhos de libertação dos povos de origem africana em todas as Américas, prisioneiros de um racismo cruel de múltiplas dimensões. No Brasil, enfrentando o tabu da "democracia racial", o Teatro Experimental do Negro era a única voz a encampar consistentemente a postura política da négritude, no sentido de priorizar a valorização da personalidade e cultura específicas ao negro como caminho de combate ao racismo.

Para concretizar seu projeto de interferir, em prol da comunidade de origem africana, no processo de elaboração da nova constituição do país, organizou a Convenção Nacional do Negro (São Paulo, 1945, e Rio, 1946). Resumindo na sua "Declaração Final" o anseio e as aspirações coletivas do grupo negro, a convenção encaminhou à Constituinte de 1946 (através do Senador Hamilton Nogueira) sua proposta de inserir a discriminação racial como crime de lesa-pátria, com uma série de medidas práticas em prol de sua eliminação. Pouco conhecidos são esses antecedentes da lei antidiscriminatória que ficou conhecida, posteriormente, como Lei Afonso Arinos. Realizou ainda o histórico I Congresso do Negro Brasileiro, no Rio de Janeiro, em 1950, cujo documentário está publicado no livro O negro revoltado (1968).

Outro integrante que foi fundamental ao TEN foi Guerreiro Ramos (1957) também ligado a proposta do ISEB ${ }^{17}$, no sentido de se constituir em uma liderança

17 ISEB (instituto Superior de Estudos Brasileiros) foi criado pelo Decreto no 37.608 , de 14 de
julho de 1955, como órgão do Ministério da Educação e Cultura. O grupo de intelectuais que
o criou tinha como objetivos o estudo, o ensino e a divulgação das ciências sociais, cujos

Latitude, Vol.2, nº1, pp.64-81, 2008. 
intelectual e ideológica para o país, da qual decorresse uma posição de liderança política efetiva. Para Guerreiro Ramos negro era o povo brasileiro, não fazendo sentido se falar em uma "questão negra". Nos anos sessenta é forçado a migrar para os EUA onde passa a desenvolver pesquisas de cunho acadêmico se afastando da perspectiva de militância política.

\section{Politização da categoria raça}

Após o período 1920-40 quando o Brasil já se supunha estar em pleno desenvolvimentismo econômico, com um setor industrial em expansão, cresce a noção de que o Brasil, assim como, a América Latina teriam, como discute Florestam Fernandes (1967), membro da escola sociológica paulista, constituído uma ordem capitalista: com uma grande parcela de "destituídos sociais". O Brasil, em vias de modernização, deveria sob o novo discurso da intelligentsia, avançar em seu processo de democratização das instituições sociais. Os intelectuais passam a se vincularem ao 'povo': "Falando ao povo (a respeito dos problemas do povo), o intelectual passava ser povo e então seu porta voz, e então intelectual da sociedade, não intelectual da anti-sociedade ${ }^{\prime 18}$. Como já referido anteriormente, o intelectual é aquele 'agregado' situado 'entre' e não simplesmente acima das classes podendo atuar na eliminação do traço de classe social de origem e alinhar-se ora com as elites ora com as massas populares.

A busca dos "sentimentos das massas" assim como "agir em nome dos interesses o povo", essa foi à nova abordagem das questões sociais da época,

(...) Ir pôr todos os meios, ao encontro do povo, ensiná-lo e deixar-se ensinar pôr ele, fundir-se com ele e, ao mesmo tempo, oferecer-lhe um espelho onde pudesse descobrir a imagem do que era, apesar de ainda não o saber: a própria nação. Tudo o que pretendiam os "pensadores" do ISEB (Instituto Superior de Estudos Brasileiros, criado por decreto em 1955) era formular o "sentimento das massas. ${ }^{19}$

Os estudos sobre as relações raciais no Brasil, desenvolvidos a partir da Universidade de São Paulo, com a participação de Roger Bastide e Florestan

dados e categorias seriam aplicados à análise e à compreensão crítica da realidade brasileira e deveriam permitir o incentivo e a promoção do desenvolvimento nacional. O ISEB foi um dos centros mais importantes de elaboração teórica de um projeto que ficou conhecido como "nacional-desenvolvimentista". Dentro do ISEB, os principais formuladores do projeto de desenvolvimento nacional foram Hélio Jaguaribe, Guerreiro Ramos, Cândido Mendes de Almeida, Álvaro Vieira Pinto e Nelson Werneck Sodré.

${ }^{18}$ Apud Ortiz (1985, p.72).

${ }^{19}$ Pécaut (1990, p.108). 
Fernandes, por solicitação da UNESCO estavam voltadas para o esclarecimento de qual seria a situação racial no Brasil. Nessa época, também houve estudos realizados por norte-americanos, dentre eles Charles Wagley e Marvin Harris mencionados no capítulo Preconceito de marca e preconceito de origem do livro de Oracy Nogueira Nem preto, nem branco (1954). A questão central nesses estudos era observar em que medida o panorama racial brasileiro seria diferente da situação nos EUA e em outras partes do mundo, como na África do Sul.

Florestan Fernandes (1967) foi um dos principais críticos do pensamento de Gilberto Freire (1933) que segundo o autor construiu uma imagem idílica que escamoteou as contradições sócias presentes nas relações entre negros e brancos na ideologia da democracia racial.

A análise apresentada por Florestan Fernandes em A integração do negro na sociedade de classes (1967) sustenta que a finalização do regime escravocrata, ou seja, a mudança no status legal de negros e mulatos não se refletiu numa mudança substancial de sua posição social. Em seu argumento, o despreparo para atuação enquanto trabalhadores livres em termos técnicos, da formação profissional e ao limitado volume de habilidades sociais adquiridas durante a escravidão somou-se à exclusão das oportunidades sociais e econômicas da nova ordem da economia liberal capitalista. Portanto os ex-escravos e homens livres de cor foram submetidos à marginalização econômica e social.

A questão racial se afastava de seu viés culturalista. Ocorria uma gradual politização da categoria raça. A questão apontada por Florestan da degeneração da família negra, sua suposta desorganização resultante do período escravista, como explicações para a condição de marginalização social será objeto de uma avaliação incisiva mais tarde nos anos 70 feita por Hasenbalg (1979) em "Discriminação e desigualdades sócias no Brasil". O autor demonstra que Florestan constrói a idéia de preconceito e discriminação racial no Brasil, conseqüente do escravismo desvinculada do então dinamismo social pós-abolição. $\mathrm{O}$ racismo seria um fenômeno de atraso cultural, devido ao ritmo desigual de mudança das várias dimensões dos sistemas econômico, social e cultural.

Tomando-se a rede de relações raciais como se apresenta em nossos dias poderia parecer que a desigualdade econômica, social e política existente entre "negro" e "branco" fosse fruto do preconceito de cor e da discriminação racial. A análise histórico sociológica patenteia, porém que esses mecanismos possuem outra função: a de manter a distância social e o padrão correspondente de isolamento sócio cultural conservado em bloco pela simples perpetuação indefinida de estruturas parciais arcaicas. Portanto, qualquer que venha a ser, posteriormente, a importância da dinâmica do preconceito de cor e da discriminação racial, eles não criaram a realidade pungente que nos preocupa. ${ }^{20}$

${ }^{20}$ Fernandes (1965, p. 193). 
Hasenbalg ainda constata que para Florestan Fernandes não é importante observar o preconceito e a discriminação raciais como parte resultante da mudança legal de status dos negros.

(...) a persistência desse preconceito e discriminação constitui um fenômeno de atraso cultural. As atitudes, comportamentos $e$ valores do antigo regime social referentes às relações raciais são mantidos em situações histórico-sociais em que estão em conflito com os fundamentos econômicos, legais e morais da ordem social vigente. A esse respeito, as manifestações de preconceito e discriminação raciais nada têm a ver com a competição ou a rivalidade entre negros e brancos nem com o agravamento real ou possível entre as tensões raciais. Elas são a expressão de mecanismos que de fato perpetuam o passado no presente. Elas representam a continuação da desigualdade racial tal como se dava no antigo sistema de castas $^{21}$.

Florestan Prefere a abordagem via classes sociais para enunciar o problema de estratificação da sociedade brasileira. O racismo como resultante de uma superestrutura é interpretado de maneira pejorativa em relação às condições sociais dos negros.

\section{A pluralidade contemporânea da categoria raça}

No período em que se seguiram os anos do regime militar a sociedade civil esteve retraída, contudo em diversas localidades do país houve vários grupos mobilizados em relação às questões raciais. Em Porto Alegre, o Grupo Palmares promove a comemoração do dia da consciência negra em no dia 20 de novembro, data relacionada à morte de Zumbi de Palmares. Essa comemoração vinha como uma demonstração de repúdio ao dia 13 de maio data relacionada à lei Áurea. No final dos anos setenta ocorre a criação do Movimento Negro Unificado (MNU) como parte do processo político em torno da redemocratização do país.

Nos anos 80 surge o conceito de quilombismo, categoria de afirmação negra afrocêntrica e de influencia marxista foi criada por Abdias do Nascimento. Defendia uma luta antiimperialista e nacionalista dos negros brasileiros respeitando-se as diferenças culturais. As condições de desigualdade e ausência de liberdade política que sempre existiram independentemente dos regimes liberais ou mais autoritários. O quilombismo foi usado como um instrumento de redemocratização no Brasil a partir do olhar da négritude. Personalidades políticas como Abdias do Nascimento na condição de senador e Benedita da Silva foram responsáveis pela implantação do debate na esfera parlamentar do debate das

${ }^{21}$ Fernandes (apud Hasenbalg, 1979, p 74).

Latitude, Vol.2, nº1, pp.64-81, 2008. 
ações afirmativas para negros. Fernando Henrique Cardoso na condição de presidente da república admite que o Brasil é um país racista ao contrário do que se veiculava até então no discurso oficial parlamentar e cria em 2000 um comitê para participar em 2001 ocorre $3^{a}$ Conferência da ONU contra o Racismo, a Discriminação Racial, a Xenofobia e a Intolerância Correlata, ocorrido, em Durban, na África do Sul em que o Brasil.

O debate intelectual na contemporaneidade sobre a categoria raça adquire uma maior amplitude em função de uma maior estruturação dos atores sociais envolvidos seja na condição de militantes advindos dos movimentos sociais, assim como, de indivíduos que atuam como pesquisadores em instituições como universidades e fundações. A diversidade contempla vários posicionamentos como o de Antonio Sergio Guimarães que em Racismo e Anti-racismo no Brasil (2002) defende a perspectiva do fim da categoria "raça". Para isso, o autor lança mão de alguns argumentos fundamentais. O primeiro se refere aos avanços na biologia que comprova a idéia de que não existem raças biológicas, segundo Penna (2005) as diferenças raciais se limita a no máximo $0,001 \%$ do genoma do homo sapiens. Em segundo, esta que o conceito de "raça" é resultante de uma interpretação científica de cunho político racista. E em terceiro o uso do termo "raça" é uma categoria política abusiva. Para os anti-racistas como Gilroy (1998), "raça" é uma categoria possível de auto-identificação para pessoas "cujos pleitos legais, oposicionistas e mesmos democráticos têm necessariamente de ser construídos sobre identidades e solidariedades forjadas a grande custo, a partir de categorias que foram impostas pelos seus opressores". No entanto "a negritude pode significar prestígio vital, invés de abjeção" 22 .

A afirmação do conceito de raça está ligada à necessidade dos anti-racistas evidenciarem as desigualdades e das diferenças estabelecidas anteriormente a partir da idéia de raça. Segundo o autor "já não precisamos historicamente da identidade racial para avançar nossos pontos de vista" naturalmente no contexto brasileiro e provavelmente até no contexto internacional tal afirmação encontra bastante resistência. Gilroy afirma que na medida em que forem superadas as desigualdades estabelecidas "não precisamos da idéia de raça seja biológica, seja social". "Raça" é não apenas uma categoria política necessária para organizar a resistência ao racismo no Brasil, mas é também uma categoria analítica indispensável: a única que revela as discriminações e desigualdades que a noção de "cor" enseja são efetivamente raciais e não apenas de "classe" 23 .

Guimarães (2002), discute as atuais variações no conceito de raça a partir das posições tomadas pelos movimentos anti-racistas. Em termos gerais há os grupos os quais se afiliam a crenças racialistas de determinação biológica de qualidades morais. Esses grupos estariam normalmente distantes do debate acadêmico mais próximo da cultura de massas.

\footnotetext{
${ }^{22}$ Gilroy (apud Guimarães, 2002, p 49).

${ }^{23}$ Gilroy (apud Guimarães, 2002, p 50).
} 
O segundo discurso desconsidera a idéia de raças biológicas e se vincula a idéia de "raças sociais" naturalizando a construção social das identidades e classificações raciais, ou seja, as "raças sociais" são construções estáveis que devem ser defendidas e preservadas no contexto da luta anti-racista.

Uma terceira posição defende o fim da idéia de raça no aspecto biológico e social como uma maneira de superação dos preconceitos racistas. Para essas pessoas a idéia de raça tende em algum momento a gerar o racismo.

Por fim uma quarta posição defende num primeiro momento a superação da idéia de raça em termos biológicos. Num segundo momento a defesa da denuncia da hierarquização do sentido de raça em termos de uma relação de positividade e negatividade. Uma vez superada estas distinções hierárquicas em torno da idéia de "raça" ela ainda teria validade em temos conceituais para compreender certas representações sociais ainda informadas pela idéia de raça.

\section{Considerações Finais}

É possível inferir que mesmo com as investidas do Estado Novo no sentido da construção de identidade racial centrada em princípios universais, a partir das categorias mulato ou mestiço, essas categorias se mantêm numa relação de oposição dentro e fora da ordem, numa espécie de "ética difusa". Trata-se de uma identidade nacional que não é simplesmente "legitimadora", produto de uma intelligentsia, mas também uma identidade de resistência de atores sociais estigmatizados pelas relações de poder forma de sobrevivência de modo distinto que norteiam as instituições como o Estado. Os movimentos sociais são de extrema relevância nesses contrapontos.

É possível considerar que elementos de negatividade e ao mesmo tempo de positividade das estimas do brasileiro no que se refere a sua identidade nacional encontrem resposta em seu processo sócio histórico avaliado pela perspectiva das classes sociais. Por outro lado, a categoria "raça" tem a capacidade em termos analíticos de revelar aspectos inerentes ao processo de construção da pobreza que a abordagem tradicional, das classes sociais, dificilmente poderia vislumbrar por si só.

\section{Bibliografia}

ALMEIDA, M. A. Memórias de um sargento de milícias. São Paulo: Ed. Publifolha, 1997.

BONFIM, M. A América Latina e seus males de origem. Rio de Janeiro: Ed. Topbooks, 1993.

CÂNDIDO, A. Dialética da malandragem. Revista do Instituto de Estudos Brasileiros, número 8, pp.67-89, 1970.

Latitude, Vol.2, nº 1, pp.64-81, 2008. 
DAMATTA, R. Carnavais, malandros e heróis: Para uma sociologia do dilema brasileiro. Rio de Janeiro: Ed. Rocco, 1997.

FERNADES, F. A integração do negro na sociedade de classes. São Paulo: Dominus Editora, 1967. . As classes sociais na América Latina. Rio de Janeiro: Paz e Terra, 1977.

FOUCALT, M. A ordem do discurso: aula inaugural no Collège de France, Pronunciada em 2/12/1970. $5^{a}$ ed. São Paulo: Ed. Loyola, 1999. . A microfísica do poder. $9^{a}$ ed. Rio de Janeiro: Ed. Graal, 1990.

GARCIA, M. Os arcanos da cidadania: a imprensa negra paulista nos primódios do século XX. (Dissertação de mestrado). São Paulo: FFLCH USP, 1997

GIDDENS, A. As conseqüências da modernidade. São Paulo: Ed. Unesp, 1991.

GILROY, P. O atlântico negro. Modernidade e dupla consciência. Rio de Janeiro: UCAM; São Paulo: Editora 34, 2001.

GOTO, R. Malandragem revisitada. Uma leitura ideológica de dialética da malandragem. Campinas: Pontes, 1988.

GRAMSCI, A. Os intelectuais e a organização da cultura. Rio de Janeiro: Ed. Civilização Brasileira, 1978.

GUIMARÃES, A. S. A. Racismo e anti-racismo no Brasil. São Paulo: Fundação de Apoio a Universidade de São Paulo; Editora 34, 2002.

Classes, raças e democracia. São Paulo: Fundação de Apoio a Unniversidade de São Paulo: Editora 34, 2002.

LEITE, D. M. O caráter nacional brasileiro: História de uma ideologia. (4a ed. definitiva). São Paulo: Pioneira, 1983.

HASENBALG, C. A. Discriminação e desigualdades raciais no Brasil. Rio de Janeiro: Graal, 1979.

MANNHEIM, K. Sociologia da cultura. São Paulo: Perspectiva; Editora da Universidade de São Paulo, 1974.

MICELI, S. Intelectuais e a classe dirigente no Brasil. (1920-1945). São Paulo: Difel, 1979.

MOREIRA, D. Relatório de Desenvolvimento Humano. Racismo, pobreza e violência PNUD. São Paulo: Prima Página, 2005.

MUNANGA, K. Rediscutindo a mestiçagem no Brasil. Petrópolis: Vozes, 1999.

NASCIMENTO, A. O negro revoltado. Rio de Janeiro: Edições GRD, 1968. 2002.

O Quilombismo. Rio de Janeiro: OR- Produtor Cultural Independente,

PÉCAUT, D. Os intelectuais e a politica no Brasil: entre o povo e a nação. São Paulo: Ática, 1990.

RODRIGUES, R. N. As raças humanas e a responsabilidade penal no país. Salvador: Livraria Progresso Editora, 1957.

SANTOS, J. A. Imprensa negra: a voz e a vez da raça na história dos trabalhadores brasileiros. Porto Alegre: UFRGS, 2005.

Latitude, Vol.2, nº1, pp.64-81, 2008. 
SANTOS, M. V. M. Nasce a Academia SPHAN. Revista do Patrimônio Histórico e Artístico Nacional, Brasília, nº. 24, pp. 77-95, 1996.

SKIDMORE, T. Preto no Branco. Raça e nacionalidade no pensamento brasileiro. Rio de Janeiro: Paz e Terra. 1976.

SODRÉ, M. Sobre imprensa negra. Lumina - Facom/UFJF, Vol. 1, no. 1, pp. 23-32, jul./ dez., 1998.

SODRÉ, N. W. Posição e responsabilidade dos intelectuais. Encontros com a Civilização Brasileira. Rio de Janeiro: Civilização Brasileira, nº. 18, pp. 99-122, 1979.

TORRES, A. Senso, consciência e caráter nacional. In: O problema nacional brasileiro: Introdução a um problema de organização nacional. $4^{\mathrm{a}}$ ed., Cia. Editora Nacional/UnB, Brasília, 1982, pp. 28-29.

VELlOSO, M. P. Os intelectuais e a política cultural do Estado Novo. Rio de Janeiro: Centro de Pesquisa e Documentação de História Contemporânea da do Brasil, 1987. 